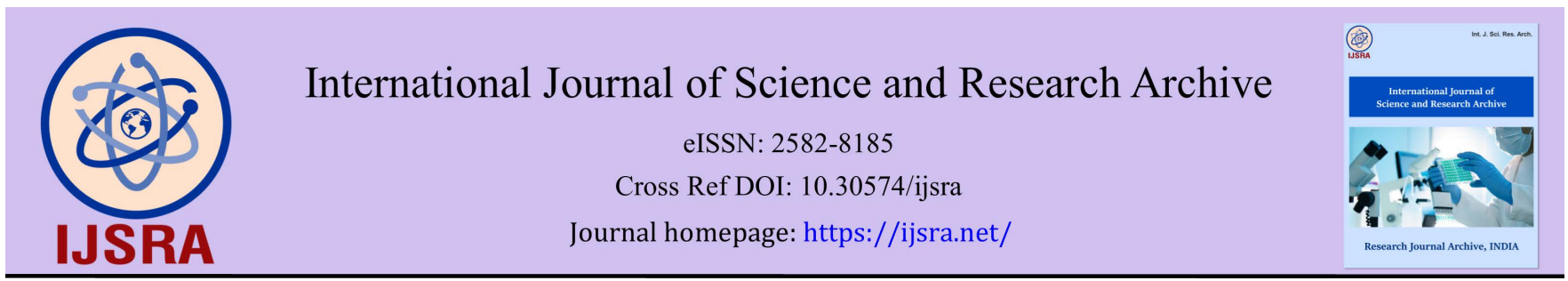

(RESEARCH ARTiClE)

\title{
Formulation and evaluation of herbal ointment using leaves of Acacia nilotica (L.) Delile extract
}

\author{
Samanta Krishanu * \\ Pharmacy College Azamgarh, Itaura, Chandeshwar, Azamgarh 276128, Uttar Pradesh, India.
}

International Journal of Science and Research Archive, 2021, 02(01), 125-130

Publication history: Received on 13 January 2021; revised on 17 February 2021; accepted on 19 February 2021

Article DOI: https://doi.org/10.30574/ijsra.2021.2.1.0029

\begin{abstract}
Diseases have co-existed with life, the study of diseases and their treatment is important part of our ancient plant worldwide. Herbal plants are wonderful origin of traditional \& modern medicine, useful for primary health care system. Herbal medicine prepare various part of plant are used. Instead off an herbal drug is design as the alternative formulation for the external use in the form of ointment. For the medicinal use the herbal ointment apply externally on human body. The main aims of this research are preparation of herbal ointment from the Acacia nilotica (L.) Delile plants the antibacterial activity. Under this research work, it is design as herbal ointment with the help of ethanolic extract of Acacia nilotica (L.) Delile determines the anti-bacterial capacity on it. In vitro study the antibacterial activity of the ethanolic extracts of dried leaves of Acacia nilotica (L.) Delile are determine by using the Agar cup plate method versus different bacteria such as Staphylococcus aureus, Bacillus subtilis, Escherichia coli and Pseudomonas aeruginosa etc. By blending the ethanolic extract of Acacia nilotica (L.) Delile $(10 \% \mathrm{w} / \mathrm{w})$ into aqueous cream we formulated herbal ointment. The emulsifying agent and simple ointment bases are added in above herbal ointment for increase the antibacterial effectiveness during in vitro evaluation. Acacia nilotica (Family Leguminosae) are broadly used in traditional system of medicine throughout different part of India, Africa \& America. It is used in the treatment of diarrhea, dysentery, cough, tuberculosis and leprosy. The current study deals with the determination of formulation and evaluation of herbal ointment using Acacia nilotica (L.) leave extract.
\end{abstract}

Keywords: Acacia nilotica; Herbal ointment; Staphylococcus aureu; Escherichia coli; Leguminosae; Babool

\section{Introduction}

In current days herbal ointment is more popular formulation use for external application. The conveying of drugs through the skin are encouraging concept because easy of access, large surface area, vast exposure to the circulatory and lymphatic networks and protective nature of the treatment [1]. Instead of the alternative formulation like herbal medicine may also be prepared in the form of ointment. These ointment mention a viscous semisolid preparation applied externally on body surfaces area such as the skin, mucus membranes of the eye, vagina, anus, and nose etc. These ointments have medical properties. The medicated ointments contain a medicinal ingredient mixed, suspended or emulsified in the ointment base. Herbal ointment applied externally such as antipruritic, keratolytics, protectants, antiseptics, emollients and astringents. Ointment bases are mainly free from water and generally contain one or more chemical in suspension or solution or dispersion form. Hence Ointment bases may be different types like absorption bases, dehydrating hydrocarbon water soluble type [2].

Herbal plants have ability for the formation of secondary metabolites such as steroids, phenolic substances, flavonoids, alkaloids, etc. These secondary metabolites are used to treatment of many diseases. Acacia nilotica belonging to the family Leguminosae brought its importance for its different traditional uses throughout India. On folklore study Acacia

${ }^{*}$ Corresponding author: Krishanu Samanta

Assistant professor Pharmacy College Itaura, Chandeshwar, Azamgarh 276128 Uttar pradesh, India.

Copyright (C) 2021 Author(s) retain the copyright of this article. This article is published under the terms of the Creative Commons Attribution Liscense 4.0. 
nilotica have more therapeutic importance. There are about 1200 species found in tropical and subtropical region of Asia, South America, Africa and Australia. Acacia nilotica contains many chemical constituents like- gallic acid, arabic acid, chlorogenic acid. [3]. Acacia nilotica is useful against multidrug resistant of bacteria and fungus causing nosocomial and community acquired infections. Phytochemical analysis of different parts of Acacia nilotica shows different classes of secondary metabolites which have therapeutic potential [4]. It is known as Babool, Kikar (Hindi), Babul (Marathi \& Bengali), Babaria (Gujrati), Babli (Kannada) Nallatumma (Telugu). It is small to medium sized tree. Its bark has dark brown to almost black. Leaves are evergreen with 4-8 pinnate and flowers in spherical heads on the new growth. Root part used in treatment of tuberculosis, it is also used in cancerous tumour of (eye \& ear). Leaf part used to treat diarrhea \& alzheimer"s disease, it is also used as emulsifying agent, suspending agent. Stem part is used as antioxidant, astringent \& emollient. Bark contains tannins, saponins, terpenoids, gallic acid, and leaf part contain cresol (antiseptic). The other chemical constituent of Acacia is arabic acid which on hydrolysis gives L-arabinose, L-rhamnose, D-galactose, Dglucuronic acid. Others species of babool are Vachellia nilotica, Acacia arabica. [5]

Today in the modern era, the pathogenic bacteria have developed resistance against existing antibiotics because of the extensive use of antimicrobial drugs against the infectious diseases. So some of the active compounds prohibit growth of the disease causing microbes either singly or in combinations [6]. For a long period of time plants have been a precious source of natural products which are used for maintain the human health, especially in last decades with more extensive studies for natural treatments. There is a continuous and immediate need to invent the new antimicrobials compounds with the varied chemical structure and innovative mechanisms of action for new and re -appearing infectious diseases. So scientists are increasingly turning their attention to community medicines, looking for new leads to develop better drugs against microbial infections [7]. Considering that extracts of Acacia nilotica (L.) Delile show broad spectrum antimicrobial activity. The aim of the study was to show that Acacia nilotica (L.) Delile are antibacterial activity and also has high potential as antibacterial agent when synthesized as ointment for topical use ethanolic extract of Acacia nilotica (L.) Delile. Acacia nilotica (L.) Delile belonging to the family Leguminosae brought its importance for its different traditional uses throughout India. It is used in the treatment of various diseases such as colds, diarrhea, dysentery, bleeding piles and bronchitis [8]. The aim of the current study deal the formulation and evaluation of herbal ointment using Acacia nilotica (L.) Delile extract.

\section{Material and methods}

Fresh leaves parts of Acacia nilotica (L.) Delile were collected from fields of Chandeshwar, district of Azamgarh, Uttar Pradesh, India in the month of January 2018 and authenticated by Prof N.K Dubey, Taxonomist, Department of Botany Banaras Hindu University, Varanasi-221005, Uttar Pradesh, India. A voucher specimen has been preserved in Department of Natural Product, Pharmacy college, Azamgarh, Uttar Pradesh, India for future reference (Voucher specimen no.Mimosa.2018/3). The leaves parts were dried under shade and powdered (40 mesh size) and stored in airtight containers. The macroscopic characters were studies as per given procedure in WHO guidelines on quality control methods for medicinal plants materials [9].

\section{Macroscopical studies}

The leaves of the plant were studied for their macroscopic characters such as color, odour, taste, shape and size of the leaf.

\section{Physicochemical studies}

The loss of drying $[10,12]$, extractive values (petroleum ether $60-80{ }^{\circ} \mathrm{C}$, ethanol, chloroform, benzene, aqueous)were determined according to the official methods of ayurvedic pharmacopoeia of India [11,13-15], were performed according to the official methods prescribed in Indian Herbal Pharmacopeia [16]. and WHO guidelines [17].

\subsection{Test microorganisms}

The microorganisms used for the study were Staphylococcus aureus and Escherichia coli. In this study, multi drug resistant wound separates bacteria from pathology, Civil Line, Azamgarh were used. The bacterial strains were raised and managed on Mueller Hinton agar at $37^{\circ} \mathrm{C}$. 


\subsection{Microbiological media}

Chemicals and standard drugs Mueller Hinton Agar and Nutrient broth are collect from the Chemical store of the Pharmacy College, Azamgarh. Gentamicin ointment (1mg of Gentamicin in the form of Gentamicin Sulphate), obtain by medical store of Maha Mrityunjay Hospital, Azamgarh.

\subsection{Preparation of ethanolic extract of Acacia nilotica (L.) Delile (EEAN) leaves}

The sun-dried leaves of Acacia nilotica (L.) Delile powdered 4g of milled leaves powder are extracted with ethanol by maceration for $48 \mathrm{hr}$. The extracts are filter and concentrate using evaporator at $35^{\circ} \mathrm{C}$ to obtain semisolid extract. The extracts are stored in a desiccator. (EEAN) prepare at different concentrations of $500 \mathrm{mg} / \mathrm{ml}, 250 \mathrm{mg} / \mathrm{ml} \mathrm{and} 100 \mathrm{mg} / \mathrm{ml}$.

\subsection{Evaluation of antibacterial activity of Extract}

The antibacterial activity of the ethanolic extract of the leaves of Acacia nilotica (L.) Delile (EEAN) at concentrations of $100 \mathrm{mg} / \mathrm{ml}, 250 \mathrm{mg} / \mathrm{ml}$ and $500 \mathrm{mg} / \mathrm{ml}$ were determined using the cup plate method. A molten Mueller Hinton agar stabilized at $45^{\circ} \mathrm{C}$ was seeded with $0.1 \mathrm{ml}$ of a $24 \mathrm{~h}$ broth culture of the test organism ( E. coli and S. aureus) containing approximately $10^{8} \mathrm{cfu} / \mathrm{ml}$ in a sterile petri dish and allowed to set. Wells of $6 \mathrm{~mm}$ diameter were created with a sterile cork borer and filled to about three-quarters full with solutions of the ethanolic extract of the leaves of Acacia nilotica (L.) Delile (EEAN). The plates were pre-incubated for $1 \mathrm{~h}$ at room temperature to allow for diffusion of the solution and then incubated for $24 \mathrm{~h}$. The zones of inhibition were measured (mean, $\mathrm{n}=2$ ). Streptomycin and Gentamycin were used as positive and negative controls respectively. The in vitro bacterial response to the extract are evaluate using the diameter of the zones of inhibition as follows; resistant: $10 \mathrm{~mm}$ and below, intermediate: $11-15 \mathrm{~mm}$ and susceptible: $16 \mathrm{~mm}$ and above. [18]

\subsection{Preparation of Ointments}

Three topical ointment bases of varying degrees of aqueous/anhydrous character namely simple ointment BP, emulsifying ointment BP and aqueous cream BP were prepare by fusion method. In this method the constituents of the base were placed together in a melting pan and allowed to melt together at $70^{\circ} \mathrm{C}$. After melting, the ingredients were stirred gently maintaining temperature of $70^{\circ} \mathrm{C}$ for about 5 minutes and then cooled with continuous stirring. Formulation of ointment done by incorporating $10 \mathrm{~g}$ of the semisolid ethanolic extract of Acacia nilotica (into the various bases by triturating in a ceramic mortar with a pestle to obtain $100 \mathrm{~g}$ of herbal ointments containing $10 \% \mathrm{w} / \mathrm{w}$ of Acacia nilotica extract [19]. The prepared herbal ointments were put in ointment tube, labeled and were stored at room temperature.

\subsection{Evaluation of ointment}

The evaluations were carried out on the ointment by using the following parameters.

\subsubsection{Colour and odour}

Colour and odour of ointment, examine by visual examination.

\subsubsection{Loss on drying}

$1 \mathrm{~g}$ of ointment was placed in the Petridis and heated in the water bath at $105{ }^{\circ} \mathrm{C}$ every $30 \mathrm{~min}$ until it get constant weight.

\subsection{3. $p H$}

The $\mathrm{pH}$ of ointment was determined by digital $\mathrm{pH}$ meter. $1 \mathrm{~g}$ of ointment was dissolved in $50 \mathrm{ml}$ of distilled water and the $\mathrm{pH}$ was measured.

\subsubsection{Diffusion study}

The diffusion study was carried out by preparing agar nutrient medium of any concentration. It was poured into Petridis. A hole bored at the centre and ointment was placed in it. The time taken for the ointment to get diffused was noted.

\subsubsection{Stability study}

The stability studies are carried out for the prepared ointment at temperature of $37^{\circ} \mathrm{C}$ for 2 months. 


\section{Results and discussion}

The preliminary in vitro antimicrobial activity of the ethanolic extract of Acacia nilotica (L.) Delile (EEAN) presented showed excellent activity against Staphylococcus aureus. The in vitro antimicrobial activity of the ethanolic extract of Acacia nilotica (L.) Delile (EEAN) based herbal ointments. In various case history show that most of the infections are caused by the gram-positive bacteria such as Staphylococcus aureus and Streptococcus pyogenes. Less common cause by the gram-negative bacteria such as Escherichia coli. The ethanolic extract of Acacia nilotica (L.) Delile (EEAN) leaves showed significant antibacterial activity against all the tested microorganisms. This observation indicates that the activity due to the presence of large varieties of phytoconstitunets present in the extract. Hence the observed antibacterial activities of the ointment are due to the presence of active constituents of the extract and the activity also possess as ointment. This was good sign to do further studies on that to make it as one of the commercial ointment for the treatment of bacterial infections. In literature survey it was found that the plant possesses several traditional and pharmacological uses. The formulation and evaluation of herbal ointment study of the leaves extract of Acacia nilotica (L.) Delile were done. The leaves were ever green in color. The values of the physical constant like loss on drying, extractive value were determined. Extractive value and color of extract was investigated (Table-2).

Table 1 Macroscopical evaluation of Acacia nilotica (L.) leaves

\begin{tabular}{|l|l|l|}
\hline S. No. & Feature & Observation \\
\hline 1. & Color & Green \\
\hline 2. & Odour & Characteristics \\
\hline 3. & Taste & Astringent \\
\hline 4. & Size & Avg. 4-20 $\mathrm{mm}$ long \\
\hline
\end{tabular}

Table 2 Physiochemical Analysis of Acacia nilotica (L.) Leaves

\begin{tabular}{|l|l|l|l|l|}
\hline S. No. & Solvent & Wt. of Plant material (gm) & \%age of yield & Color of extract \\
\hline 1. & Chloroform & 4 & $5 \%$ & Greenish Brown \\
\hline 2. & Pet. Ether & 4 & $1.80 \%$ & Greenish Brown \\
\hline 3. & Ethanol & 4 & $7.8 \%$ & Greenish \\
\hline 4. & Benzene & 4 & $7.5 \%$ & Pale green \\
\hline 5. & Aqueous & 4 & $4.75 \%$ & Yellowish brown \\
\hline
\end{tabular}

Table 3 Composition of the ethanolic extract of Acacia nilotica (L.) Delile leaves ointment

\begin{tabular}{|l|l|l|}
\hline S. No. & Components & Amount(gm) \\
\hline 1. & Ethanolic extract of leaves Plant Acacia nilotica (L.) Delile & 2 \\
\hline 2. & Emulsifying wax & 28 \\
\hline 3. & White soft paraffin & 50 \\
\hline 4. & Liquid paraffin & 20 \\
\hline
\end{tabular}

Table 4 Physicochemical parameters of Acacia nilotica (L.) Delile herbal ointment formulation.

\begin{tabular}{|l|l|l|}
\hline S. No & Physicochemical parameters & Observation \\
\hline 1. & Colour & Dark greenish \\
\hline 2. & Odour and taste & Characteristic \\
\hline 3. & Loss of drying & $0.18 \%$ \\
\hline 4. & pH & 6.2 \\
\hline 5. & Diffusion study & $2.1 \mathrm{~cm}$ in $1 \mathrm{~min}$ \\
\hline 6. & Stability study & Stable with $\mathrm{pH} 6.1$ \\
\hline
\end{tabular}


Table 5 zone of inhibition of the ethanolic extract of Acacia nilotica (L.) Delile (EEAN) leaves

\begin{tabular}{|l|l|l|l|}
\hline S. No & Concentration $(\mathbf{m g} / \mathbf{m L})$ of MEEO & Staphylococcus aureus & Escherichia coli \\
\hline 1. & 100 & $12.67 \pm 3.06$ & $11.00 \pm 2.00$ \\
\hline 2. & 250 & $14.67 \pm 1.53$ & $13.00 \pm 2.00$ \\
\hline 3. & 500 & $17.00 \pm 2.00$ & $16.33 \pm 3.05$ \\
\hline 4. & Ciprofloxacin $(5 \mu \mathrm{g})$ & $29.33 \pm 3.06$ & $27.00 \pm 3.00$ \\
\hline
\end{tabular}

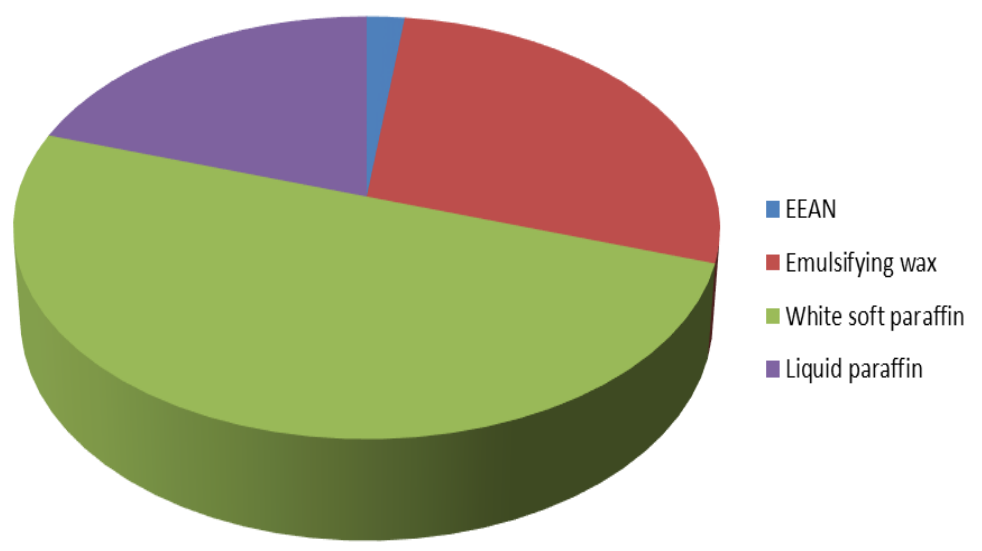

Figure 1 Composition of the ethanolic extract of Acacia nilotica (L.) Delile leaves ointment

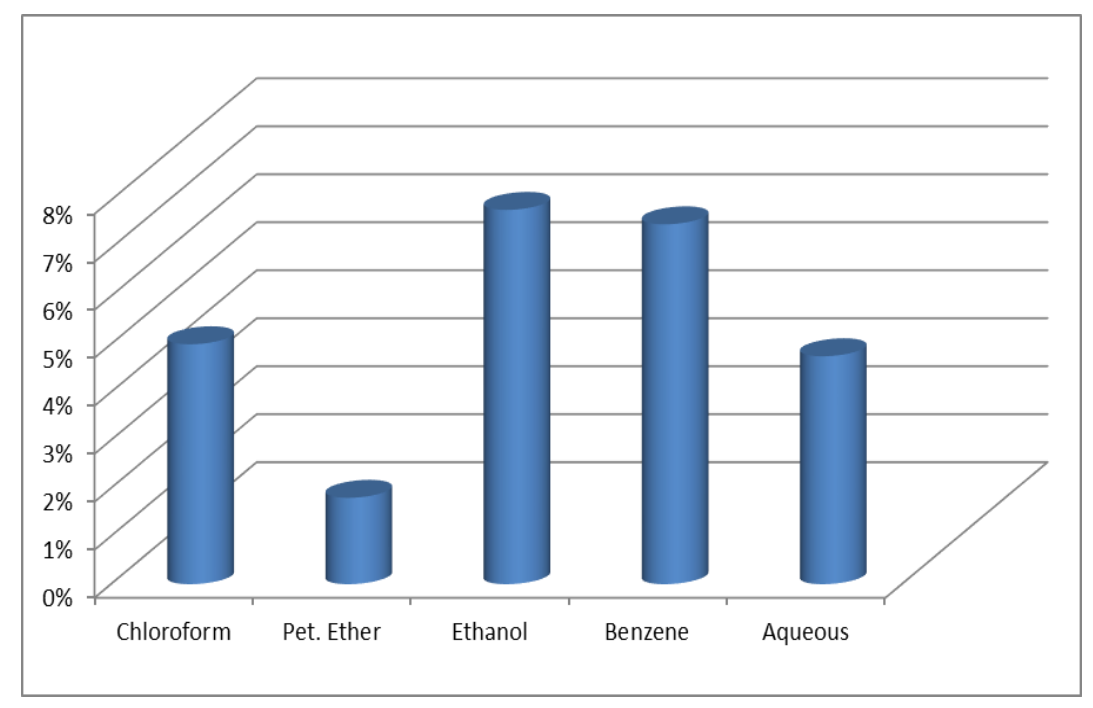

Figure 2 Physiochemical Analysis of Acacia nilotica (L.) Leaves

\section{Conclusion}

In concluded that the present investigation comes out with the fact that Acacia nilotica (L.) Delile essential oil are required so that better, safe and cost effective drugs for treating $S$. aureus causing diseases. This study shows that Acacia nilotica (L.) Delile are antibacterial activity and have high potential as antibacterial agent. When formulated as ointment for topical use and could therefore explain the successes claimed in the folk use of the plant in the treatment of common skin conditions. The potency of the Acacia nilotica (L.) Delile herbal ointment against Staphylococcus aureus could be harnessed in the containment of the organism implicated as the commonest etiologic agent of boils, carbuncles, infantile- impetigo and wound. The final product readily spread on skin surface, showed no irritant effect, diffused well and stable at different temperature. It also require to research on phytochemical and pharmacological aspect. However research going on it would be easier to develop new formulation. 


\section{Compliance with ethical standards}

\section{Acknowledgments}

Authors express sincerely thanks to Dr. Emdad Hossain, principal, Pharmacy College, Azamgarh, Uttar Pradesh for providing research facilities

\section{References}

[1] Sukanya MK, Shimi, Aruna SR. Phytochemical Analysis Antimicrobial Analysis Antimicrobial careening and Anthelmintic properties Of Phyllanthusemblica. International Journal of Pharma and Bio Sciences. 2013; 4(4):5564.

[2] Bhandari PR, Kamdod MA. Emblicaofficinalis (Amla): A review of potential therapeutic applications. 2012; 6(4):257-269.

[3] Leela V, Saraswathy A; Pharmacognostic studies on the flowers of the Acacia niloticaLinn, Pharmacognosy Journal. March- April 2012; 4: 35-39.

[4] Singh Rupal, Thakur Rupesh; Phytochemical analysis and antibacterial activity of Acacia nolotica Linn. Against pathogenic bacteria; International Journal of Green Pharmacy. April- June 2016;10: 106-110.

[5] Deshpandey SN; Preliminary phytochemical analysis and in vitro investigation of antibacterial activity of Acacia niloticaagainst clinical isolates; J PhamacognPhytochem. 2003; 1.

[6] Maji S, Dandapat P, Ojha D, Maity C, Halder SK, Das PK et al. In vitro antimicrobial potentialities of different solvent extracts of ethnomedicinal plants against clinically isolated human pathogens. Journal of Phytology. 2010; 2(4):57-64.

[7] Yadav A, Samanta K, Formulation and Evaluation of Herbal Ointment using Emblicaofficinalisextract,WJARR. 2021; 09(2): 032-037.

[8] Samanta K, Patel N, Preliminary physico-phytochemical and phyto-cognosticalevaluation of the leaves of Acacia nilotica(L) IJPCS. 2019; 8(1): 14-17.

[9] Pratt RJ, Chase CR. J Am Pharm Assoc. 1949; 38: 324-333.

[10] Bhatia D, Gupta M. K, Gupta A. M and Kaithwas J. Nat Pro Rad. 2008; 7: 326.

[11] The Ayurvedic Pharmacopoeia of India, 1(2),(Govt. of India, Ministry of Health and Family Welfare), New Delhi.

[12] Anonymous. Indian Pharmacopeia, Volume 1, The Indian Pharmacopoeia commission, Ghaziabad. $2010 ; 82-201$.

[13] Pharmacopoeia of India, Ministry of Health and family Welfare, Govt of India, New Delhi, 1996, 2:53-95.

[14] India Pharmacopoeia, controller of Publication, Delhi. 1996; 1: 209-210.

[15] World Health Organization, Geneva; Quality Control Method for Medicinal Plant Materials, Geneva. 1998; 9: 2233.

[16] Anonymous. Indian Herbal Pharmacopeia, Volume 1, Indian Drug Manufacturers Association, Mumbai. 1998; 179-197.

[17] World Health Organization, Geneva; Quality Control Method for Medicinal Plant Materials, A.I.T.B.S. Publisher and Distributors, New Delhi. 2002; 8-24.

[18] Singh J, Kaur S. Phyllanthus embilica Leaves Extract a Potential Amylase enzyme Inhibitor with antioxidant and antimicrobial activity. International Journal of Pharmacological Research.2019; 5(9): 200-206.

[19] Guideline2.1.-Laboratoty methodologies for bacterial antimicrobial susceptibility testing.OIE Terrestrial manual. 2012;1-11. 